\title{
Genetic parameters for atypical reproductive patterns in dairy cows estimated from in-line milk progesterone profiles
}

\author{
R. van Binsbergen, ${ }^{*}$ ๑ A. C. Bouwman, $\odot$ and R. F. Veerkamp $\odot$ \\ Wageningen University \& Research, Animal Breeding and Genomics, $6700 \mathrm{AH}$ Wageningen, the Netherlands
}

\begin{abstract}
Our aim was to estimate genetic parameters of atypical reproductive patterns and estimate their genetic correlation with milk production and classical fertility traits for commercial dairy cows. In contrast with classical fertility traits, atypical reproductive patterns based on in-line milk progesterone profiles might have higher heritability and lower genetic correlation with milk production. We had in-line milk progesterone profiles available for 12,046 cycles in 4,170 lactations of 2,589 primiparous and multiparous cows (mainly Holstein Friesian) from 14 herds. Based on progesterone profiles, 5 types of atypical reproductive patterns in a lactation were defined: delayed ovulation types I and II, persistent corpus luteum types I and II, and late embryo mortality. These atypical patterns were detected in $14 \%$ (persistent corpus luteum type II) to $21 \%$ (persistent corpus luteum type I) of lactations. In $47 \%$ of lactations, at least 1 atypical pattern was detected. Threshold model heritabilities for atypical reproduction patterns ranged between 0.03 and 0.14 and for most traits were slightly higher compared with classical fertility traits. The genetic correlation between milk yield and calving interval was 0.56 , whereas genetic correlations between milk yield and atypical reproductive patterns ranged between -0.02 and 0.33 . Although most of these correlations between milk yield and atypical reproductive patterns are still unfavorable, they are lower compared with the correlations between classical fertility traits and milk yield. Therefore selection against atypical reproductive patterns may relax some constraints in current dairy breeding programs, to enhance genetic progress in both fertility and milk yield at a steady pace. However, as long as the target trait for fertility is calving interval, atypical reproductive
\end{abstract}

Received January 22, 2019.

Accepted August 22, 2019.

*Corresponding author: rianne.vanbinsbergen@wur.nl patterns will not add additional value to the breeding goal in the near future due to the low number of available records.

Key words: fertility, endocrine, heritability, genetic correlation

\section{INTRODUCTION}

Fertile cows are important in dairy breeding. Fertile cows are those that return early to cyclicity after calving and have normal estrous cycles. A normal cycle consists of 2 phases: the follicular phase and the luteal phase (Senger, 2005). During the follicular phase, ovarian follicles are growing in 2 or 3 waves until ovulation takes place. These follicular waves result in episodes of elevated estrogen and reduced progesterone levels during the follicular phase. After ovulation, the luteal phase starts with the development of the corpus luteum, which is marked by low estrogen and high progesterone levels. Without successful pregnancy, the luteal phase ends with luteolysis, which causes a decline in progesterone level, and a new cycle will start. Due to the large differences in progesterone levels during the 2 phases, the reproductive status of a cow could be defined by measuring progesterone levels in blood plasma or milk.

Regular (e.g., daily) progesterone measurements are preferred to define the 2 phases in the estrous cycle. However, measuring progesterone levels on a large number of cows is very labor intensive. Therefore, classical fertility traits based on calving and insemination records are used in breeding programs as a measure of the reproductive status of a cow. The advantage of classical fertility traits is that calving and insemination dates are routinely recorded in the national database for many dairy cows, at least in the Netherlands. The disadvantage is the low heritability of such traits (e.g., for calving interval between 0.01 and 0.07 ; reviewed by Berry et al., 2014) and the positive, and therefore unfavorable, genetic correlation with milk production traits. For example, in their review, Berry et al. (2014) reported a pooled genetic correlation of $0.38( \pm 0.04)$ between milk yield and interval between first and last insemina- 
tion. The assumption is that insemination dates reflect the moment of a cow in heat. However, this is strongly influenced by recording errors and reproductive farm management. For example, heat signals can be missed, inseminations might not be (properly) recorded, or a farmer can decide to inseminate the cow later in lactation. Preferential treatment of high-producing cows (e.g., by delaying rebreeding or by inseminating more often) might bias heritability and correlation estimates, although these estimates are genetic (Pryce et al., 1997). Therefore, we need fertility measures that are less subject to this bias and that better indicate the reproductive status of the cow.

With progesterone measurements, endocrine fertility traits such as commencement of luteal activity (C-LA), luteal phase length (LPL), and interluteal interval (ILI) can be defined. These endocrine fertility traits reflect the true reproductive status of a cow and are not biased by reproductive farm management. These endocrine fertility traits generally have higher heritability estimates (e.g., for C-LA, between 0.12 and 0.24; Berry et al., 2014; Tenghe et al., 2015; Häggman et al., 2018) compared with classical fertility traits. Besides these endocrine fertility traits that describe typical luteal cycles, atypical luteal cycles can also be defined based on measurements of progesterone level. Previous studies analyzed atypical reproductive patterns for a limited number of cows and were based on progesterone levels measured 2 or 3 times weekly (Lamming and Darwash, 1998; Opsomer et al., 1998; Nyman et al., 2014). With the development of in-line systems such as the Herd Navigator (DeLaval International, Tumba, Sweden), milk progesterone levels can be recorded automatically at informative moments during the luteal cycle. This generates progesterone profiles of relatively large numbers of lactations compared with clinical trials conducted so far. Although the in-line progesterone level measurements might be less precise than such clinical trials, the frequency of sampling and number of lactations sampled is higher, which makes such data suitable for genetic parameter estimation.

Based on the progesterone level profiles described above, 5 types of atypical reproductive patterns can be defined: prolonged C-LA, prolonged ILI (e.g., caused by a follicular cyst), prolonged LPL in the first cycle, prolonged LPL in the second or later cycles before insemination (e.g., caused by a luteal cyst), and late embryo mortality (prolonged LPL after insemination). Our aim in this study was to estimate genetic parameters of atypical reproductive patterns defined from in-line milk progesterone profiles and estimate their genetic correlation with milk production and classical fertility traits for dairy cows from 14 commercial herds and 1 research herd.

\section{MATERIALS AND METHODS}

The study initially included records of 14 Dutch commercial dairy herds and 1 Dutch research herd. On each of these herds a Herd Navigator (DeLaval International, Tumba, Sweden) was installed. The Herd Navigator takes milk samples on a regular basis and measures progesterone levels. Raw progesterone level measurements were smoothed using an extended Kalman filter, to reduce random noise. These values were fitted into a biological model to predict the reproductive status of the cow and to determine the sampling interval (Friggens and Chagunda, 2005; Friggens et al., 2008). In total 373,155 smoothed progesterone level measurements for 3,611 cows were available for the period between June 2012 and March 2016.

Insemination, lactation, and milk production records, as well as pedigree information, were obtained from the national database (CRV, Arnhem, the Netherlands). The pedigree included 31,849 animals. Only phenotypic information of cows with pedigree information available was used in this study. This pedigree information also included the breed of the cows. The Holstein Friesian breed was most common in the data set: $97.4 \%$ of the cows were at least one-eighth Holstein Friesian. Other breeds that were present in the data set were Brown Swiss (9.6\% of the cows), Dutch Friesian (9.1\%), Fleckvieh $(9.1 \%)$, and Meuse-Rhine-Yssel (14.9\%). Another $13.2 \%$ of the cows were (partly) from other breeds (Swedish Red, Norwegian Red, Jersey, Montbéliarde, Piemontese, Belgian Blue, Limousin) or the breed composition was (partly) unknown. Insemination records were available for 41,021 inseminations of 6,006 cows from these farms. Lactation and milk production records were available for 14,880 lactations of 4,764 cows from these farms, and these cows were born between March 1996 and June 2014. For 1 herd, no lactation and milk production records were available; therefore, this herd was excluded from the analyses. The remaining analyses were done on 14 herds in total: 13 commercial herds and 1 research herd. Milk production records included 305-d milk yield, 305-d fat yield, and $305-d$ protein yield. Fat and protein percentages were calculated by dividing 305-d fat and protein yields by the total 305-d milk yield and then multiplying by 100 . Classical fertility traits, endocrine fertility traits, and atypical reproductive patterns were defined based on lactation, insemination, and progesterone level records, as will be described.

\section{Classical Fertility Traits}

Classical fertility traits were defined per cow per lactation. Edits for classical fertility traits were performed 
at cow level and lactation level. The thresholds used were based on edits described by the Dutch national herd book (CRV Cooperative, 2018). Cows were taken into account only if the minimum age of the cow was $640 \mathrm{~d}$ when calving the first time. Classical fertility traits were taken into account only for lactations without embryo flushing or embryo transplantation. Classical traits could be defined for 12,114 lactations of 4,259 cows from 14 herds. For the smallest herd, 461 lactations were available from 151 cows, whereas the largest herd contributed 1,530 lactations from 450 cows. Overall, the parity of the cows was, on average, $2.6(\mathrm{SD}=1.6)$ and ranged between 1 and 15 . The average 305 -d milk production was $8,797 \mathrm{~kg}(\mathrm{SD}=1,936$ $\mathrm{kg} ; 11,147$ lactations) and ranged between 6,957 and 9,940 kg per herd (Table 1).

Calving Interval. Calving interval (CInt) was defined as the number of days between calving date of the current lactation and calving date of the next lactation, and should be between 210 and $800 \mathrm{~d}$. If either of these dates was unknown in our data set, CInt was set to "missing." If the time between 2 consecutive inseminations was more than $150 \mathrm{~d}$ (indicator of early abortion), or if the time between the last insemination and calving was more than $400 \mathrm{~d}$, CInt was set to "missing."

Interval Between Calving and First Service. Interval between calving and first service (CFS) was restricted between 30 and $250 \mathrm{~d}$. When a cow was kept with a bull before the first insemination, CFS was set to "missing."

Interval Between First and Last Insemination. Interval between first and last insemination (IFL) was equal to 1 if only 1 insemination took place or if re-insemination took place within $4 \mathrm{~d}$. If CFS was not between 30 and $250 \mathrm{~d}$, or when a cow was kept with a bull, IFL was set to "missing." Moreover, if no calving was observed following insemination and fewer than $300 \mathrm{~d}$ elapsed between last insemination and the last calving date in the data set, IFL was set to "missing." As described by the Dutch national herd book (CRV Cooperative, 2018), IFL was increased by 57 penalty days (the average number of days for a cow to become pregnant; de Haer et al., 2013) if no calving was observed following insemination and at least $300 \mathrm{~d}$ elapsed between last insemination and the last calving date in the data set. This increase of 57 penalty days was also performed if CInt was more than $800 \mathrm{~d}$ or if time from last insemination until calving was not between 265 and $300 \mathrm{~d}$. If the time between 2 consecutive inseminations was more than $150 \mathrm{~d}$, IFL was calculated for the inseminations before this interval of $150 \mathrm{~d}$ plus 57 penalty days. If the number of days from last insemination until calving was more than $300 \mathrm{~d}$ and there was a valid CInt, then IFL $=$ CInt - CFS $-280 \mathrm{~d}$ (average length of bovine pregnancy is $280 \mathrm{~d}$ ). Finally, IFL was restricted to $220 \mathrm{~d}$ (without penalty days).

\section{Endocrine Fertility Traits}

In contrast to the classical traits, endocrine fertility traits were defined per cow per luteal cycle, based on regular milk progesterone level measurements. These progesterone level measurements were fitted into a biological model to determine the sampling interval (Friggens et al., 2008), which was on average 1 measurement every $2.32 \mathrm{~d}(\mathrm{SD}=1.96)$, but close to ovulation the frequency increased to once a day or even 1 measurement every milking. A lactation was removed if parity was unknown, if progesterone measurements started after 35 d postpartum, or if the sampling interval between 2 consecutive measurements was equal or larger than $14 \mathrm{~d}$. If the sampling interval between 2 consecutive measurements was less than $5 \mathrm{~min}$, the second measurement was removed from the data. After edits, 255,833 progesterone level measurements were available for 4,170 lactations (136 to 564 lactations per herd) on

Table 1. Descriptive statistics per lactation (number, mean, SD, minimum, and maximum) and minimum and maximum herd means for production traits ${ }^{1}$ and classical fertility traits ${ }^{2}$ after quality control

\begin{tabular}{|c|c|c|c|c|c|c|c|}
\hline Trait & $\begin{array}{l}\text { Number of } \\
\text { lactations }\end{array}$ & Mean & SD & Min & Max & Min herd mean & Max herd mean \\
\hline MY (kg) & 11,147 & 8,797 & 1,936 & 1,228 & 16,349 & 6,957 & 9,940 \\
\hline $\mathrm{FP}$ & 11,147 & 4.34 & 0.43 & 2.89 & 7.60 & 4.09 & 4.66 \\
\hline CInt (d) & 7,720 & 408.2 & 65.3 & 230 & 767 & 383.2 & 430.0 \\
\hline CFS (d) & 10,197 & 91.1 & 35.8 & 30 & 250 & 78.9 & 118.4 \\
\hline IFL (d) & 10,048 & 47.5 & 55.0 & 1 & 311 & 13.3 & 61.8 \\
\hline
\end{tabular}

${ }^{1} \mathrm{MY}=305$-d milk yield; $\mathrm{FP}=305$-d fat percentage; $\mathrm{PP}=305$-d protein percentage.

${ }^{2} \mathrm{CInt}=$ calving interval; $\mathrm{CFS}=$ interval between calving and first insemination; IFL $=$ interval between first and last insemination; No. AI = number of inseminations. 


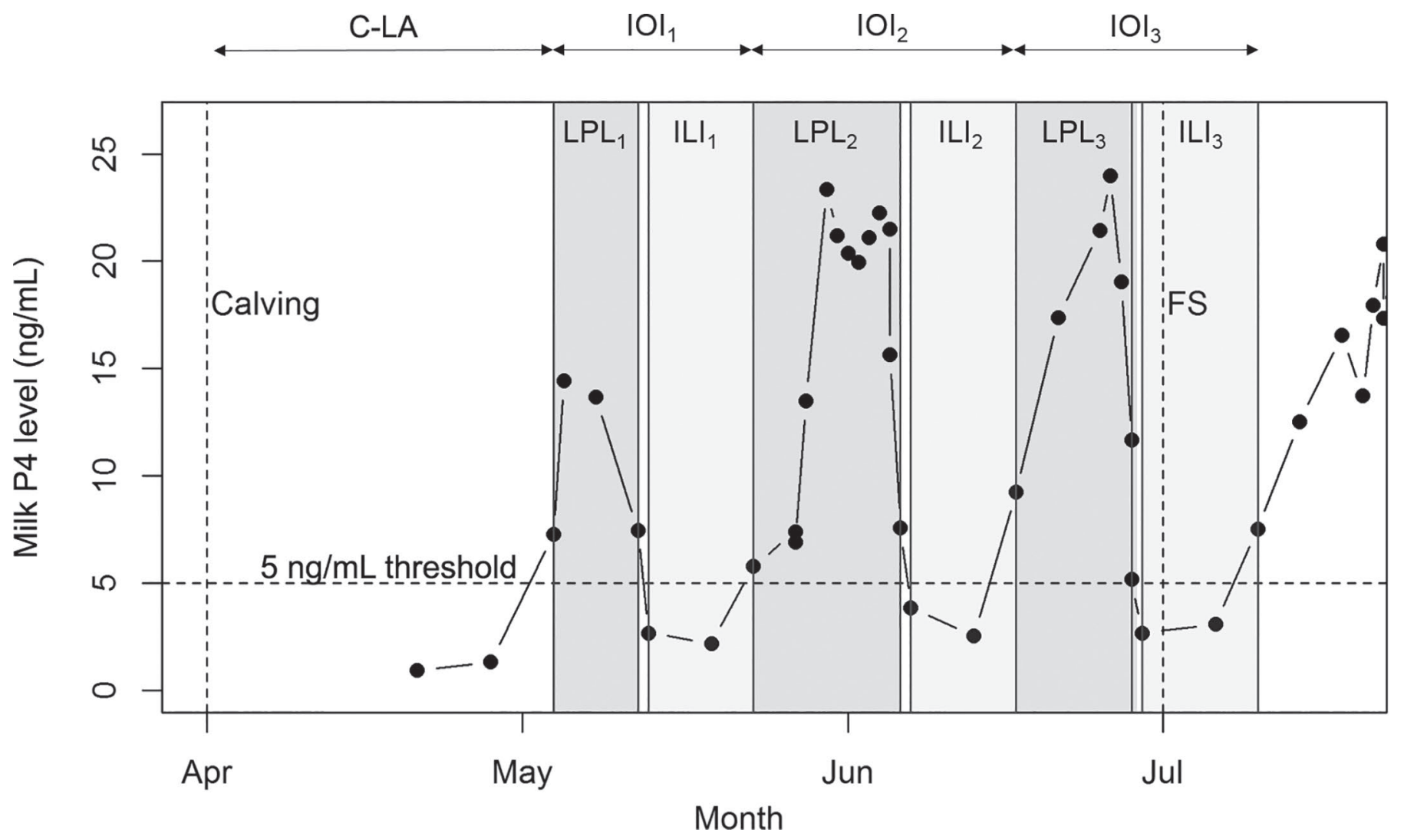

Figure 1. Example of a milk progesterone (P4) profile of 1 lactation of an individual cow, to show the definitions of endocrine fertility traits. $\mathrm{C}-\mathrm{LA}=$ commencement of luteal activity; $\mathrm{LPL}_{n}=$ luteal phase length of cycle $n$; $\mathrm{ILI}_{n}=$ length of interluteal phase interval of cycle $n$; IOI ${ }_{n}=$ length of interovulatory interval of cycle $n ; \mathrm{FS}=$ first service. The dotted horizontal line represents the threshold $(5 \mathrm{ng} / \mathrm{mL})$ for luteal activity.

2,589 cows (89 to 294 cows per herd). The traits were defined for all luteal cycles from start of lactation until the first luteal cycle after first insemination. Figure 1 shows a graphical representation of the definitions of the endocrine traits.

Commencement of Luteal Activity. The definition of C-LA was the number of days between calving and start of luteal activity. Luteal activity was defined as the period with elevated milk progesterone level $(\geq 5$ $\mathrm{ng} / \mathrm{mL}$ ). Start of luteal activity was defined as the first day with elevated milk progesterone level $(\geq 5 \mathrm{ng} / \mathrm{mL})$, under the condition that the next consecutive sample also showed an elevated milk progesterone level.

Luteal Phase Length. The definition of LPL was the number of days of luteal activity in a cycle, which was equal to the interval from the start of luteal activity until the last consecutive day of elevated milk progesterone level ( $\geq 5 \mathrm{ng} / \mathrm{mL}$ ).

Length of Interluteal Interval. The definition of ILI was the number of days of nonluteal activity after a period of luteal activity. The start of this nonluteal activity period was defined as the first day with de- creased milk progesterone level $(<5 \mathrm{ng} / \mathrm{mL})$. The end of the nonluteal activity period was defined as the start of luteal activity of the next cycle.

Length of Interovulatory Interval. The interovulatory interval (IOI) referred to the total length of the cycle, which was defined as the interval from start of luteal activity for the cycle until start of luteal activity for the next cycle. Due to the definitions of the traits, there could be a slight difference between IOI and the sum of LPL and ILI - that is, the last consecutive day of elevated milk progesterone level (end of LPL) and the first day with decreased milk progesterone level (start of ILI) could differ $\geq 1 \mathrm{~d}$ due to nondaily measurements.

Number of Cycles Until First Insemination. The last endocrine fertility trait in this study was number of cycles until first insemination. This includes the cycle in which insemination took place.

\section{Atypical Reproductive Patterns}

Based on the endocrine fertility traits described, 6 additional traits were defined to describe atypi- 
cal reproduction patterns. The trait definitions were similar to the definitions described by Lamming and Darwash (1998). Lactations were defined as atypical if they showed prolonged C-LA, LPL, or ILI. To define prolonged C-LA, LPL, or ILI, a data set with "typical" records (all records excluding outliers with a trait value larger than the mean plus $3 \mathrm{SD}$ ) was used. If a pattern in lactation exceeded the mean C-LA, LPL, or ILI plus 1 standard deviation of this "typical" data set, this pattern was considered atypical. When an atypical pattern occurred in a lactation, the trait value was equal to 1 ; otherwise it was equal to 0 . The atypical traits were defined per cow per lactation.

Delayed Ovulation Type I. Delayed ovulation type I (DOVI) describes a prolonged period of nonluteal activity after calving. The trait value for a lactation was 1 when C-LA $\geq 54 \mathrm{~d}$, else DOVI $=0$.

Delayed Ovulation Type II. Delayed ovulation type II (DOVII) describes a prolonged period of nonluteal activity after a period of luteal activity. The trait value for a lactation was 1 when in at least 1 cycle ILI $\geq 16 \mathrm{~d}$, else DOVII $=0$.

Persistent Corpus Luteum Type I. Persistent corpus luteum type I (PCLI) describes prolonged luteal activity in the first cycle after calving. The trait value for a lactation was 1 when $\mathrm{LPL} \geq 20 \mathrm{~d}$ in the first cycle, else PCLI $=0$.

Persistent Corpus Luteum Type II. Persistent corpus luteum type II (PCLII) describes prolonged luteal activity in the second or later cycle before first insemination. The trait value for a lactation was 1 when $\mathrm{LPL} \geq 20 \mathrm{~d}$ in at least 1 of second or later cycles before first insemination, else PCLII $=0$.

Late Embryo Mortality. Late embryo mortality (LEM) describes prolonged luteal activity in the cycle after first insemination. This trait indicates successful insemination but unsuccessful pregnancy. The trait value for a lactation was 1 when LPL $\geq 20 \mathrm{~d}$ in the cycle after first insemination, else $\mathrm{LEM}=0$.

Total. The trait total (TOT) describes whether the lactation showed any atypical patterns. Total was 0 for lactation with no atypical reproductive patterns, and $\mathrm{TOT}=1$ for lactations with 1 or more of the atypical reproductive patterns previously described.

Please note that endocrine fertility traits and atypical patterns were based on Herd Navigator progesterone measures in combination with insemination and calving records, and were not confirmed by clinical diagnosis.

\section{Genetic Analysis}

Variance components to estimate heritabilities and genetic correlations were obtained by performing uni- variate and bivariate analyses in ASReml (version 4.1; Gilmour et al., 2015). For the analyses, a general linear mixed model was used with fixed and random effects. Fixed effects included intercept, parity class (parity was equal to $1,2,3,4$, or $\geq 5$ ), interaction between parity class and calving age, year-season at calving (where season was divided into 4 periods of 3 months: January to March, April to June, July to September, and October to December), and 5 covariates with regression on proportion of non-Holstein Friesian genes (proportion of Brown Swiss, Dutch Friesian, Fleckvieh, Meuse-Rhine-Yssel, and a fifth class including proportion of other non-Holstein Friesian breeds or unknown breed). The proportion of non-Holstein Friesian genes was fitted in the model because 4 non-Holstein Friesian breeds were well represented in the data set, and each breed has a different genetic background for fertility; in addition, crossbred animals might have heterosis benefits. Random effects included the random genetic effect of a cow, the random permanent environmental effect of a cow (to account for repeated measures within cow), and a random herd effect. The random effects were assumed to be normally distributed as $N\left(0, \mathbf{A} \sigma_{a}^{2}\right)$, $N\left(0, \mathbf{I} \sigma_{p e}^{2}\right), \quad N\left(0, \mathbf{I} \sigma_{\text {herd }}^{2}\right)$, and $N\left(0, \mathbf{I} \sigma_{e}^{2}\right)$, respectively, where $\mathbf{A}$ was the additive genetic relationship matrix, $\sigma_{a}^{2}$ the additive genetic variance, I was the identity matrix, $\sigma_{p e}^{2}$ the permanent environmental variance, $\sigma_{\text {herd }}^{2}$ the variance explained by herd, and $\sigma_{e}^{2}$ the residual variance. Pedigree information was used to build the additive genetic relationship matrix A. Heritabilities were calculated by dividing the additive genetic variance $\left(\sigma_{a}^{2}\right)$ by the total phenotypic variance $\left(\sigma_{a}^{2}+\sigma_{p e}^{2}+\sigma_{\text {herd }}^{2}+\sigma_{e}^{2}\right)$.

The model assumed a normal distribution of the data. However, observations for the traits IFL, C-LA, LPL, ILI, IOI, and number of cycles until first insemination were skewed, and therefore the natural logarithm (ln) of these traits was used. The phenotypes for the univariate analyses of the endocrine traits LPL, ILI, and IOI consisted of a record for each cycle rather than 1 record per lactation. For these analyses, an additional fixed effect for cycle class was added, which included 3 classes: first cycle, second or later cycle before first insemination, or first cycle after first insemination. For univariate analyses of the binary atypical reproductive patterns we also used a generalized linear mixed model with a probit-link function (threshold model) next to the linear model. We also used the probit-link function for bivariate analyses for the atypical reproductive patterns. The same fixed and random effects were used as described before. The year-season class January to 
March 2016 with multiple observations, but no incidence of DOVII, PCLII, or LEM, was merged with the previous year-season class (October to December 2015).

\section{RESULTS}

\section{Descriptive Statistics}

In Table 1 summary statistics for the classical fertility traits are shown. Differences were found between cow lactations, as well as between herd averages: the mean per herd for CInt ranged between 383.2 and 430.0 d, CFS between 78.9 and $118.4 \mathrm{~d}$, and IFL between 13.3 and $61.8 \mathrm{~d}$. With the 255,833 progesterone measurements, we could define 12,046 luteal cycles. On average there were 2.1 cycles (range 0 to 14 ) per lactation until first insemination. The herd mean ranged between 1.7 and 2.9 cycles in a lactation until first insemination. For these luteal cycles we defined C-LA (only first cycle), LPL, ILI, and IOI. Table 2 shows the summary statistics for C-LA, LPL, ILI, and IOI. Overall the mean C-LA was $38.3 \mathrm{~d}$, and the herd means ranged between 31.3 and $46.5 \mathrm{~d}$. For the other traits, the minimum and maximum herd means differed between 2.2 and $4.1 \mathrm{~d}$ when taking into account all cycles.

Frequencies of occurrence of atypical reproduction patterns are shown in Table 3. Overall, the frequencies ranged between $14 \%$ and $21 \%$. In $47 \%$ of the lactations, at least 1 atypical pattern was detected (TOT), and in $12.4 \%$ of the lactations more than 1 atypical pattern was detected, with 4 atypical patterns in 1 lactation as maximum. Lactations showing more atypical patterns also showed longer CInt, CFS, and IFL, as well as higher 305-d milk yield (Figure 2). We discovered differences between the frequencies of atypical patterns per herd (Table 3 ). The extreme herd minimum (0.00) and herd maximum frequency (0.59) of LEM were caused by the low number of records in those herds (1 or 17 lactations). Without those 2 herds (herds $\mathrm{H}$ and $\mathrm{J})$ the minimum frequency for LEM in a herd was 0.08 and the maximum frequency was 0.23 . The ranking of the herds differed by trait. For example, herd A had the overall lowest frequency of atypical patterns $(\mathrm{TOT}=$ 0.32); however, its frequency of DOVII was high (0.18) compared with the other herds. On the other hand, herd $\mathrm{M}$ had the second-highest frequency of atypical patterns $(\mathrm{TOT}=0.57)$ but, compared with the other herds, a relatively low frequency of atypical reproductive patterns, due to prolonged luteal phase length (PCLI, PCLII, and LEM).

\section{Genetic Parameters}

The estimated genetic parameters are shown in Table 4. Estimated heritability of milk yield was $0.16( \pm \mathrm{SE}$ 0.02 ), and the herd effect explained $27 \%$ of the total variance. For the classical fertility traits, we estimated heritabilities between $0.01( \pm 0.01)$ and $0.09( \pm 0.01)$. For the endocrine traits, the highest heritabilities were found for $\ln (\mathrm{C}-\mathrm{LA})(0.16 \pm 0.04)$ and $\ln (\mathrm{LPL})(0.13 \pm$ $0.02)$. The heritabilities of the other endocrine traits ranged between $0.03( \pm 0.01)$ and $0.07( \pm 0.02)$. In addition to a high heritability for $\ln (\mathrm{C}-\mathrm{LA})$, we also found a high permanent environment effect of $0.14( \pm 0.04)$. So $30 \%$ of the total variance of $\ln (\mathrm{C}-\mathrm{LA})$ could be explained by the individual cow effect, and therefore $\ln (\mathrm{C}-\mathrm{LA})$ was moderately repeatable. Relatively high herd effects (between 0.07 and 0.27 ) were estimated for

Table 2. Descriptive statistics per luteal cycle [cycle class, number (No. of cycles), mean, SD, minimum, and maximum] and minimum and maximum herd means for endocrine fertility traits $^{1}$ after quality control

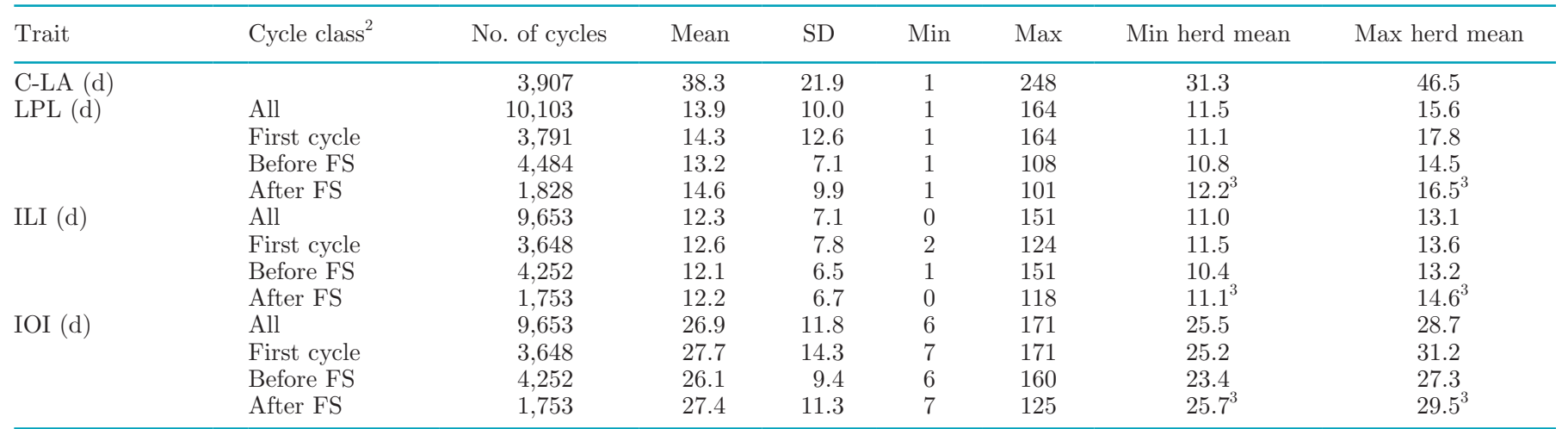

${ }^{1} \mathrm{C}-\mathrm{LA}=$ commencement of luteal activity; LPL $=$ luteal phase length; ILI = length of interluteal phase interval; IOI $=$ length of interovulatory interval.

${ }^{2}$ Three cycle classes were defined: first cycle, second or later cycle before first insemination (Before FS), and first cycle after first insemination (After FS).

${ }^{3}$ Two herds were excluded here due to limited records $(<20)$ in the cycle class After FS, 1 and 17 records, respectively. 
milk yield, CFS, $\ln (\mathrm{IFL})$, number of inseminations, and number of luteal cycles until first insemination. The herd variances of the progesterone-based traits are very small, indicating that differences in farm management had little influence on cyclicity of cows.

Heritabilities using the normal linear model for atypical reproductive patterns ranged between 0.02 $( \pm 0.02)$ for DOVII and $0.12( \pm 0.03)$ for DOVI (Table 4). Permanent environment effects for the linear model ranged between $0.03( \pm 0.03)$ and $0.18( \pm 0.05)$. With the threshold model, heritabilities were estimated between $0.03( \pm 0.04$; DOVII $)$ and $0.14( \pm 0.03$; PCLI $)$, and almost no permanent environment effects were estimated.

The fixed effects of parity showed significant effects for all atypical traits $(P<0.001)$, except PCLII $(P$ $=0.641$ ). Although parity effects were significant, we observed no general trend. In general, PCLI was highest for cows in their fifth parity or higher, DOVI was lowest for second-parity cows, DOVII was highest for third-parity cows, and LEM was slightly higher for second-parity cows. Year-season was also significant for most atypical traits $(<0.001$ to 0.036$)$ but not for PCLI $(P=0.225)$ or PCLII $(P=0.057)$. The regression on the breed proportions were only significant for PCLI, PCLII, and TOT for proportion of Fleckvieh ( $P$-values ranged between 0.004 and 0.027); for PCLII and TOT for proportion of Brown Swiss ( $P$-values between 0.012 and 0.029); and for TOT for proportion of MeuseRhine-Yssel $(P=0.049)$. Regression coefficients were all negative, suggesting that a higher proportion of the respective breeds results in fewer atypical patterns. This confirms our expectation that a higher proportion of non-Holstein breeds results in better fertility. This may be explained in 2 ways: (1) other breeds have undergone less extreme selection on milk production compared with Holsteins, resulting in fewer fertility issues, or (2) cross-breeding has heterosis benefits.

\section{Bivariate Analyses}

One part of our objective was to estimate genetic correlations between atypical reproductive patterns and milk productions traits. Therefore, we performed bivariate analyses between those traits. In the univariate analyses, the estimates for permanent environment effects were very low for most traits, so no permanent environment effect was fitted in the bivariate analyses. As with the univariate analyses, a probit-link function was used for the binary atypical reproductive patterns. No results were obtained for the bivariate analyses with PCLII as they failed, probably due to the low frequency. Genetic correlations between atypical reproductive patterns and production traits are shown in Table 5. The highest genetic correlations with production traits were found between milk yield and TOT $(0.33 \pm 0.08)$ and between milk yield and DOVII $(0.23 \pm 0.04)$. The other genetic correlations between atypical reproductive patterns and milk yield were lower: between $-0.02( \pm 0.05)$ for LEM and $0.13( \pm 0.04)$ for PCLI. In comparison, the genetic correlation between milk yield and CInt in our data set was $0.56( \pm 0.05)$, and the genetic correlation between milk yield and CFS was $0.34( \pm 0.05)$.

In addition to genetic correlation with production traits, we were also interested in the genetic correlations between atypical reproductive patterns and classical fertility traits. As shown in Table 5, the genetic correlation between the atypical reproductive patterns and CInt and CFS ranged between $0.27( \pm 0.07)$ and 0.54 $( \pm 0.05)$. For TOT the genetic correlation with CInt

Table 3. Frequency of atypical reproductive patterns per herd and (in parentheses) number of lactations with a valid record for each atypical trait within that herd ${ }^{1}$

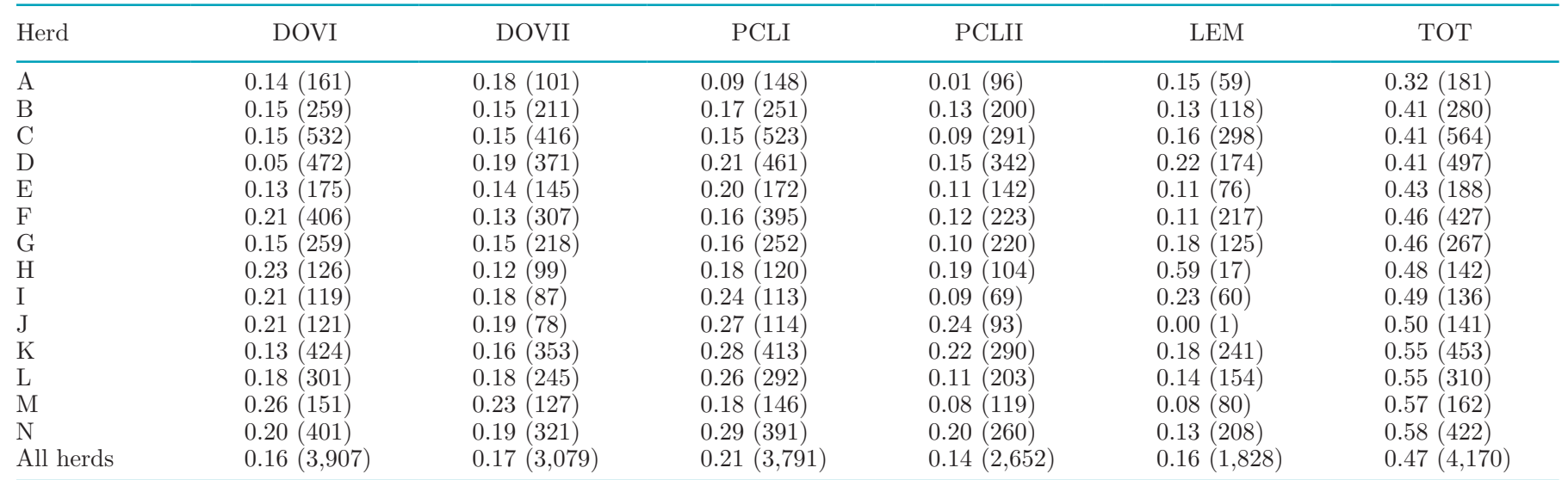

${ }^{1}$ DOVI $=$ delayed ovulation type I; DOVII = delayed ovulation type II; PCLI = persistent corpus luteum type I; PCLII = persistent corpus luteum type II; LEM = late embryo mortality; TOT $=1$ or more atypical patterns in lactation. 


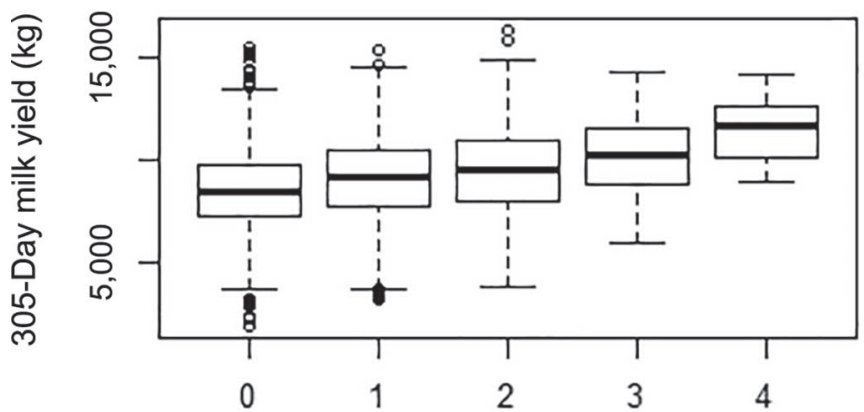

Number of atypical traits during lactation

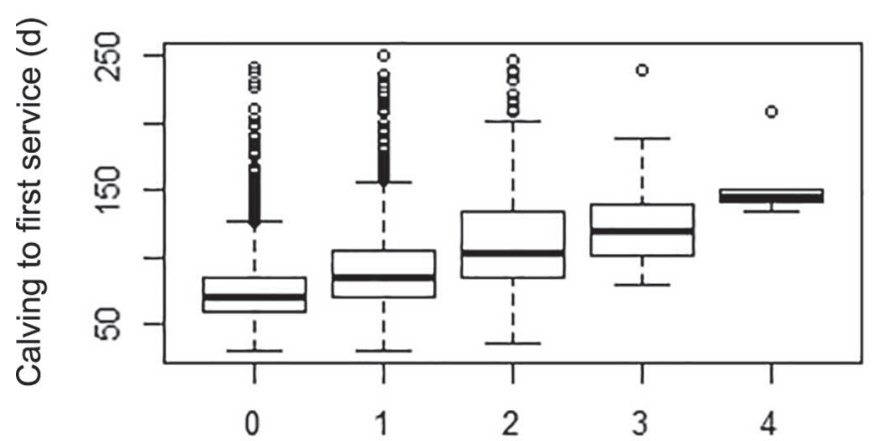

Number of atypical traits during lactation

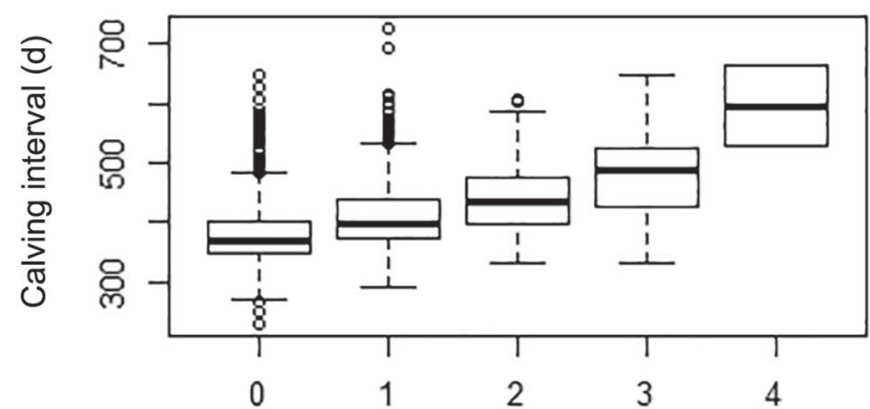

Number of atypical traits during lactation
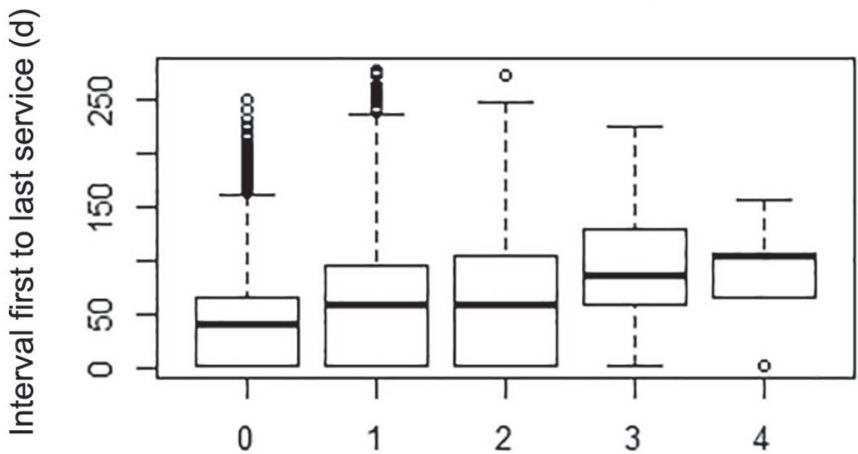

Number of atypical traits during lactation

Figure 2. Boxplot distribution of milk production and classical fertility traits per number of atypical patterns per lactation. The box represents $25-75 \%$ of the data (IQR); the band inside the box represents the median (second quartile); whiskers represent 1.5 of the IQR of the lower and upper quartile, respectively; dots represent outliers.

was $0.74( \pm 0.10)$, and the genetic correlation between TOT and CFS was $0.90( \pm 0.08)$. Genetic correlations between $0.22( \pm 0.15)$ and $0.51( \pm 0.10)$ were estimated for DOVII, PLCI, LEM, and TOT with $\ln ($ IFL) and number of inseminations, whereas DOVI showed correlations of $0.00( \pm 0.38)$ with both $\ln (\mathrm{IFL})$ and number of inseminations.

\section{DISCUSSION}

Our aim was to estimate the genetic parameters of atypical reproductive patterns and estimate their genetic correlation with milk production and classical fertility traits for dairy cows from 14 herds. Previous studies have analyzed classical fertility traits, endocrine fertility traits (reviewed in Berry et al., 2014), and atypical reproductive patterns for a limited number of cows or based on progesterone measurements performed only 2 or 3 times weekly (Lamming and Darwash, 1998; Royal et al., 2000; Nyman et al., 2014). In this study, we had 255,833 in-line milk progesterone measurements available for 2,589 cows in 14 herds. Measurement frequency was based on a biological model to determine the sampling interval (Friggens et al., 2008). The aver- age frequency was 1 measurement every $2.32 \mathrm{~d}$, but close to ovulation the frequency increased to once a day or even 1 measurement every milking. With this larger number of records, we should be able to better characterize atypical reproductive patterns and estimate genetic parameters, compared with other studies.

\section{Definitions of Atypical Reproductive Patterns}

In the literature there is currently no clear consensus on the definition of atypical reproductive patterns. In the current study we adapted a trait definition from Lamming and Darwash (1998): patterns were considered atypical if a cycle exceeded the mean C-LA, LPL, or ILI plus 1 standard deviation of a "typical" data set. This "typical" data set consisted of all records excluding outliers with a trait value larger than the mean plus 3 standard deviations. For DOVI the threshold in our study was C-LA $\geq 54 \mathrm{~d}$, whereas in other studies this threshold was set to $45 \mathrm{~d}$ (Lamming and Darwash, 1998; Royal et al., 2000), 50 d (Opsomer et al., 1998), or 56 d (Nyman et al., 2014). Our threshold for DOVII was at least 1 cycle with ILI $\geq 16 \mathrm{~d}$. Other studies had lower thresholds of $12 \mathrm{~d}$ (Lamming and 
Darwash, 1998; Royal et al., 2000) or 14 d (Opsomer et al., 1998; Nyman et al., 2014). For PCLI, PCLII, and LEM, we found more consensus in the literature with thresholds of 19 or 20 d (e.g., Lamming and Darwash, 1998; Opsomer et al., 1998; Nyman et al., 2014). For comparison between studies it is better to have more consensus in the thresholds used, or at least in the way the thresholds are defined. In the current study, we based the threshold on the analyzed data set, although it might be better to define a threshold based on a different and, if possible, larger data set. The studies previously reported used clinical data from experimental herds, whereas we used Herd Navigator data from mainly commercial herds (1 experimental herd) reared under different management conditions, resulting in more phenotypic variation and therefore somewhat different trait definitions. In addition, Herd Navigator measurements might be less accurate than clinical progesterone measures, but they are measured more frequently, smoothing is applied to overcome random noise observed in the profiles (Friggens and Chagunda, $2005)$, and a higher threshold (5 ng/mL instead of the usual $3 \mathrm{ng} / \mathrm{mL}$ ) is set for luteal activity. All this also influenced the trait definitions in our study. For instance, the physiological cycle length of cattle is $21 \mathrm{~d}$, whereas the mean IOI in our study was around $27 \mathrm{~d}$. In animal breeding, the ranking of animals according to their breeding values is key. Therefore the classification used here is functional for animal breeding. For truly defining abnormal cows, more precise classification and better measurements are needed. Given the differences in recording and studied population with previous studies, we chose to use the actual data set to optimize the thresholds, a solution that takes into account recording flaws as well as the average reproductive state of the current commercial (high-yielding) population.

\section{Heritabilities}

In contrast to the low heritabilities found for the classical fertility traits, we found slightly higher heritabilities for endocrine traits and atypical reproductive patterns. For the traits based on progesterone measures, most of the explained variation was due to genetics or

Table 4. Heritability $\left(h^{2}=\sigma_{a}^{2} / \sigma_{p}^{2}\right),{ }^{1}$ permanent environmental effect $\left(\sigma_{p e}^{2} / \sigma_{p}^{2}\right)$, and herd effect $\left(\sigma_{\text {herd }}^{2} / \sigma_{p}^{2}\right)$ for all studied traits; SE in parentheses

\begin{tabular}{|c|c|c|c|c|c|c|}
\hline \multirow[b]{2}{*}{ Trait $^{2}$} & \multicolumn{3}{|c|}{ Linear model } & \multicolumn{3}{|c|}{ Threshold model } \\
\hline & $h^{2}$ & $\left(\sigma_{p e}^{2} / \sigma_{p}^{2}\right)$ & $\left(\sigma_{\text {herd }}^{2} / \sigma_{p}^{2}\right)$ & $h^{2}$ & $\left(\sigma_{p e}^{2} / \sigma_{p}^{2}\right)$ & $\left(\sigma_{\text {herd }}^{2} / \sigma_{p}^{2}\right)$ \\
\hline FP & $0.53(0.03)$ & $0.08(0.02)$ & $0.08(0.03)$ & & & \\
\hline $\mathrm{PP}$ & $0.51(0.03)$ & $0.05(0.02)$ & $0.02(0.01)$ & & & \\
\hline \multicolumn{7}{|c|}{ Classical fertility traits } \\
\hline CInt & $0.07(0.02)$ & $0.05(0.02)$ & $0.03(0.01)$ & & & \\
\hline No. of AI & $0.01(0.01)$ & $0.05(0.01)$ & $0.07(0.02)$ & & & \\
\hline \multicolumn{7}{|c|}{ Endocrine fertility traits $^{3}$} \\
\hline $\ln (\mathrm{C}-\mathrm{LA})$ & $0.16(0.04)$ & $0.14(0.04)$ & $0.02(0.01)$ & & & \\
\hline $\ln (\mathrm{LPL})$ & $0.13(0.02)$ & $0.04(0.02)$ & $0.00(0.00)$ & & & \\
\hline $\ln (\mathrm{ILI})$ & $0.03(0.01)$ & $0.03(0.01)$ & $0.01(0.01)$ & & & \\
\hline $\ln (\mathrm{IOI})$ & $0.07(0.02)$ & $0.03(0.01)$ & $0.01(0.00)$ & & & \\
\hline $\ln$ (No. of cycles) & $0.06(0.02)$ & $0.00(0.03)$ & $0.10(0.04)$ & & & \\
\hline LEM & $0.04(0.04)$ & $0.04(0.06)$ & $0.01(0.01)$ & $0.07(0.05)$ & $0.00(0.00)$ & $0.01(0.02)$ \\
\hline TOT & $0.05(0.02)$ & $0.06(0.03)$ & $0.01(0.01)$ & $0.10(0.04)$ & $0.01(0.04)$ & $0.03(0.01)$ \\
\hline
\end{tabular}

${ }^{1}$ The total phenotypic variance $\left(\sigma_{p}^{2}\right)$ was equal to $\sigma_{a}^{2}+\sigma_{p e}^{2}+\sigma_{\text {herd }}^{2}+\sigma_{e}^{2}$, where $\sigma_{a}^{2}=$ additive genetic variance and $\sigma_{e}^{2}=$ residual variance.

${ }^{2} \mathrm{MY}=305$-d milk yield; FP $=305$-d fat percentage; $\mathrm{PP}=305$-d protein percentage; CInt $=$ calving interval; CFS $=$ interval between calving and first insemination; $\ln (\mathrm{IFL})=$ natural logarithm of interval between first and last insemination; No. of AI = number of inseminations; $\ln (\mathrm{C}$ LA) = natural logarithm of commitment of luteal activity; $\ln (\mathrm{LPL})=$ natural logarithm of luteal phase length; $\ln (\mathrm{ILI})=$ natural logarithm of length of interluteal phase interval; $\ln (\mathrm{IOI})=$ natural logarithm of length of interovulatory interval; $\ln ($ No. of cycles) = natural logarithm of number of luteal cycles until first insemination; DOVI = delayed ovulation type I; DOVII = delayed ovulation type II; PCLI = persistent corpus luteum type I; PCLII = persistent corpus luteum type II; LEM = late embryo mortality; TOT = 1 or more atypical patterns in lactation. ${ }^{3}$ For $\ln (\mathrm{LPL}), \ln (\mathrm{ILI})$, and $\ln (\mathrm{IOI})$, analyses were performed per cycle instead of per lactation. These analyses included an additional fixed effect for cycle class (first cycle, second or later cycle before first insemination, and first cycle after first insemination).

${ }^{4}$ For atypical patterns, results are shown for the normal linear model and for the threshold model using a probit-link function. 
Table 5. Genetic, herd, and phenotypic correlations (with SE) for atypical reproductive patterns ${ }^{1}$ with milk production traits ${ }^{2}$ and classical $^{3}$ fertility traits ${ }^{3}$

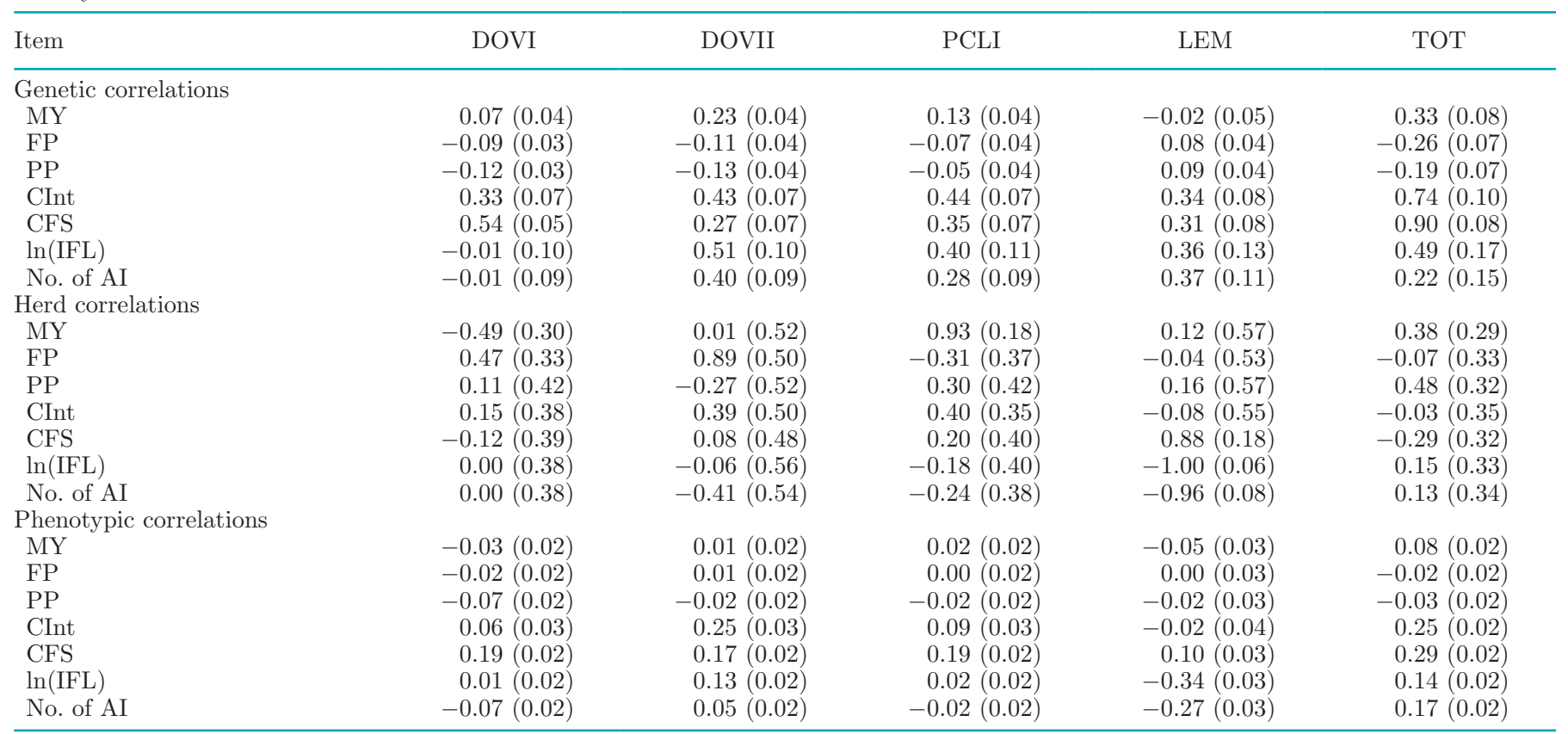

${ }^{1}$ DOVI = delayed ovulation type I; DOVII = delayed ovulation type II; PCLI = persistent corpus luteum type I; LEM = late embryo mortality; $\mathrm{TOT}=1$ or more atypical patterns in lactation.

${ }^{2} \mathrm{MY}=305$-d milk yield; $\mathrm{FP}=305$-d fat percentage $; \mathrm{PP}=305$-d protein percentage.

${ }^{3} \mathrm{CInt}=$ calving interval; CFS $=$ interval between calving and first insemination; $\ln (\mathrm{IFL})=$ natural logarithm of interval between first and last insemination; No. of $\mathrm{AI}=$ number of inseminations in a lactation.

permanent environment effects (in the case of C-LA). For traits including insemination records we saw a relatively large herd effect compared with heritability. For the endocrine traits and atypical reproductive patterns, the herd effects were close to zero and did not affect the heritability estimates (except number of cycles until first insemination, which is influenced by farmers' decisions). This indicates that heritability estimates of progesterone-based fertility traits are less subject to reproductive farm management bias.

To our knowledge, few available studies estimate heritabilities for endocrine traits, and even fewer estimate heritabilities for atypical reproductive patterns. The trait most often studied was C-LA, for which heritabilities were found between 0.12 and 0.24 (Royal et al., 2002; Nyman et al., 2014; Häggman et al., 2018). The other endocrine traits are studied less extensively in literature. Tenghe et al. (2016) found heritabilities for LPL, ILI, and IOI similar to those found in the current study; however, they used partly the same data set as used in the current study. Nyman et al. (2014) reported heritabilities for LPL and ILI of 0.08 , and for IOI of 0.03 , with standard errors ranging between 0.04 and 0.14 . Royal et al. (2002) reported an estimated heritability of $0.17( \pm 0.06)$ for LPL in the first cycle. We found 2 studies with heritability estimates for atypical reproductive patterns. The estimated heritability for PCLI $(0.13 \pm 0.06)$ found by Royal et al. (2002) was similar to the estimate found in our study $(0.14 \pm 0.03)$. Nyman et al. (2014) estimated a higher heritability for DOVI $(0.24 \pm 0.05)$, a similar heritability for DOVII $(0.00 \pm 0.04)$, and a lower heritability for PCLI $(0.02$ $\pm 0.04)$ compared with our estimates using a normal linear model. The difference in heritabilities with $\mathrm{Ny}$ man et al. (2014) might be due to differences in trait definition or to the difference in number of lactations available. In general, our heritability estimates were in line with previous estimates.

\section{Genetic Correlation with Milk Production}

An objective was to estimate genetic correlations with milk production. In general, milk production and classical fertility traits have an unfavorable genetic correlation. For example, in their review Berry et al. (2014) found a mean pooled genetic correlation of 0.46 between milk yield and CInt and of 0.14 between milk yield and CFS. The genetic correlations between milk yield and CInt and CFS in our data set were within the range of estimates reviewed by Berry et al. (2014). A reason for this unfavorable genetic correlation might be the use of insemination data, which could be biased, as 
by preferential treatment of high-producing cows or by recording errors. Although these correlation estimates were genetic, they still might be biased due to management (Pryce et al., 1997).

Endocrine traits are expected to be less subject to reproductive farm management bias and to better reflect a cow's reproductive status. Therefore, we expected that endocrine traits would have less-unfavorable genetic correlations with milk production compared with classical fertility traits. Our results showed these lessunfavorable genetic correlations of atypical reproductive patterns with milk production. Because DOVII and PCLI have higher genetic correlations with milk production than DOVI, selection for high milk yield seems to have more genetic influence on having a regular cycle than on becoming cyclic after calving.

\section{Application in Breeding Programs}

Compared with the classical fertility traits, we found slightly higher heritabilities for atypical reproductive patterns and less-unfavorable genetic correlations with milk production traits. This could be an advantage for applying these traits in breeding programs. On the other hand, the disadvantage of atypical reproductive patterns is the low number of available records, as only a limited number of farms have a system like the Herd Navigator that measures milk progesterone levels regularly. When applying a genomic selection scheme, it is better to have more cows with less-accurate phenotypes (as with classical fertility traits) than to have a limited number of cows with more accurate phenotypes (as with endocrine traits; Tenghe et al., 2018). However, 14 farms is too limited for accurate breeding value estimation, and at the moment it is too costly to routinely measure milk progesterone on farms to increase the number of records.

Due to the moderate genetic correlation with CInt (between 0.33 and 0.74 ), atypical reproductive patterns are indirectly in the breeding goal. Moreover, for farmers, the target traits will be a CInt of 1 year and conception after 1 insemination $(\mathrm{IFL}=1)$, and for these traits many records are already available in the national database. The low number of records available for atypical reproductive patterns will probably not benefit selection for these classical traits. Such an approach for adding C-LA to predict CInt or CFS was investigated by Tenghe et al. (2018), who predicted only a minor benefit of adding endocrine traits from cows to the training population for prediction of classical traits. So, if the target traits remain classical fertility traits, there is no benefit from including the new atypical reproductive patterns in the breeding program. However, from a biological or management perspective, it is still interesting, as atypical reproductive patterns can provide more details about why a bull or cow genetically has a higher chance of prolonged CInt.

\section{CONCLUSIONS}

At least 1 atypical reproductive pattern was detected in $47 \%$ of the studied lactations, and in $12 \%$ more than 1 atypical pattern was detected. In contrast to classical fertility traits, atypical reproductive patterns based on in-line milk progesterone profiles showed higher heritabilities and a less-unfavorable genetic correlation with milk production. This could be an advantage for applying these traits in breeding programs. However, as long as the target trait for fertility remains CInt, atypical reproductive patterns will not add additional value to the breeding goal in the near future, due to the low number of available records.

\section{ACKNOWLEDGMENTS}

The authors acknowledge Lattec I/S (Hillerød, Denmark) for providing in-line progesterone data and CRV BV (Arnhem, the Netherlands) for providing pedigree data and insemination, lactation, and milk production records. The study was performed as follow-up to the Prolific project (financially supported by the European Commission under the Seventh Research Framework Programme, Grant Agreement no. 311776), and the study was financed by Melkveefonds (LTO Nederland, The Hague, the Netherlands, and Wageningen University \& Research, the Netherlands).

\section{REFERENCES}

Berry, D. P., E. Wall, and J. E. Pryce. 2014. Genetics and genomics of reproductive performance in dairy and beef cattle. Animal 8(Suppl. 1):105-121. https://doi.org/10.1017/S1751731114000743.

CRV Cooperative. 2018. Chapter E-17: Breeding value fertility. In Manual Quality. CRV Cooperative, Arnhem, the Netherlands. https://www.cooperatie-crv.nl/downloads/english/e-chapters/.

de Haer, L. C. M., G. de Jong, and P. J. A. Vessies. 2013. Estimation of genetic parameters of fertility traits, for virgin heifers in the Netherlands. Interbull Bull. 47:142-146.

Friggens, N. C., M. Bjerring, C. Ridder, S. Højsgaard, and T. Larsen. 2008. Improved detection of reproductive status in dairy cows using milk progesterone measurements. Reprod. Domest. Anim. 43:113-121. https://doi.org/10.1111/j.1439-0531.2008.01150.x.

Friggens, N. C., and M. G. G. Chagunda. 2005. Prediction of the reproductive status of cattle on the basis of milk progesterone measures: Model description. Theriogenology 64:155-190. https:// doi.org/10.1016/j.theriogenology.2004.11.014.

Gilmour, A. R., B. J. Gogel, B. R. Cullis, S. J. Welham, and R. Thompson. 2015. ASReml User Guide, Release 4.1. VSN International Ltd., Hemel Hempstead, UK. www.vsni.co.uk.

Häggman, J., J. M. Christensen, E. A. Mäntysaari, and J. Juga. 2018. Genetic parameters for endocrine and traditional fertility traits, hyperketonemia and milk yield in dairy cattle. Animal 13:248-255. https://doi.org/10.1017/S1751731118001386. 
Lamming, G. E., and A. O. Darwash. 1998. The use of milk progesterone profiles to characterise components of subfertility in milked dairy cows. Anim. Reprod. Sci. 52:175-190. https://doi.org/10 .1016/S0378-4320(98)00099-2.

Nyman, S., K. Johansson, D. J. de Koning, D. P. Berry, R. F. Veerkamp, E. Wall, and B. Berglund. 2014. Genetic analysis of atypical progesterone profiles in Holstein-Friesian cows from experimental research herds. J. Dairy Sci. 97:7230-7239. https://doi .org/10.3168/jds.2014-7984.

Opsomer, G., M. Coryn, H. Deluyker, and A. Kruif. 1998. An analysis of ovarian dysfunction in high yielding dairy cows after calving based on progesterone profiles. Reprod. Domest. Anim. 33:193204. https://doi.org/10.1111/j.1439-0531.1998.tb01342.x.

Pryce, J. E., R. F. Veerkamp, R. Thompson, W. G. Hill, and G. Simm. 1997. Genetic aspects of common health disorders and measures of fertility in Holstein Friesian dairy cattle. Anim. Sci. 65:353-360. https://doi.org/10.1017/S1357729800008559.

Royal, M. D., A. O. Darwash, A. P. F. Flint, R. Webb, J. A. Woolliams, and G. E. Lamming. 2000. Declining fertility in dairy cattle: Changes in traditional and endocrine parameters of fertility. Anim. Sci. 70:487-501. https://doi.org/10.1017/S1357729800051845.

Royal, M. D., A. P. F. Flint, and J. A. Woolliams. 2002. Genetic and phenotypic relationships among endocrine and traditional fertility traits and production traits in Holstein-Friesian dairy cows. J. Dairy Sci. 85:958-967. https://doi.org/10.3168/jds.S0022 -0302(02)74155-6.
Senger, P. L. 2005. Pathways to Pregnancy and Parturition. Second rev. ed. Current Conceptions Inc., Redmond, OR

Tenghe, A. M. M., A. C. Bouwman, B. Berglund, D. J. de Koning, and R. F. Veerkamp. 2018. Improving accuracy of bulls' predicted genomic breeding values for fertility using daughters' milk progesterone profiles. J. Dairy Sci. 101:5177-5193. https://doi.org/10 .3168/jds.2016-12304.

Tenghe, A. M. M., A. C. Bouwman, B. Berglund, E. Strandberg, J. Y. Blom, and R. F. Veerkamp. 2015. Estimating genetic parameters for fertility in dairy cows from in-line milk progesterone profiles. J. Dairy Sci. 98:5763-5773. https://doi.org/10.3168/jds.2014-8732.

Tenghe, A. M. M., A. C. Bouwman, B. Berglund, E. Strandberg, D. J. de Koning, and R. F. Veerkamp. 2016. Genome-wide association study for endocrine fertility traits using single nucleotide polymorphism arrays and sequence variants in dairy cattle. J. Dairy Sci. 99:5470-5485. https://doi.org/10.3168/jds.2015-10533.

\section{ORCIDS}

R. van Binsbergen () https://orcid.org/0000-0002-4645-0221

A. C. Bouwman (® https://orcid.org/0000-0001-5079-7108

R. F. Veerkamp (ㄱ https://orcid.org/0000-0002-5240-6534 